\title{
Muscle hernias of the leg: A case report and comprehensive review of the literature
}

\author{
Jesse T Nguyen $M D^{1}$, Jenny L Nguyen $\mathrm{MD}^{2}$, Michael J Wheatley $\mathrm{MD}^{3}$, Tuan A Nguyen MD DDS FACS ${ }^{3}$
}

JT Nguyen, JL Nguyen, MJ Wheatley, TA Nguyen. Muscle hernias of the leg: A case report and comprehensive review of the literature. Can J Plast Surg 2013;21(4):243-247.

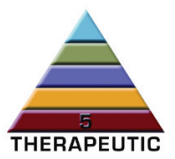

A case involving a retired, elderly male war veteran with a symptomatic peroneus brevis muscle hernia causing superficial peroneal nerve compression with chosen surgical management is presented. Symptomatic muscle hernias of the extremities occur most commonly in the leg and are a rare cause of chronic leg pain. Historically, treating military surgeons pioneered the early documentation of leg hernias observed in active military recruits. A focal fascial defect can cause a muscle to herniate, forming a variable palpable subcutaneous mass, and causing pain and potentially neuropathic symptoms with nerve involvement. While the true incidence is not known, the etiology has been classified as secondary to a congenital (or constitutional) fascial weakness, or acquired fascial defect, usually secondary to direct or indirect trauma. The highest occurrence is believed to be in young, physically active males. Involvement of the tibialis anterior is most common, although other muscles have been reported. Dynamic ultrasonography or magnetic resonance imaging is often used to confirm diagnosis and guide treatment. Most symptomatic cases respond successfully to conservative treatment, with surgery reserved for refractory cases. A variety of surgical techniques have been described, ranging from fasciotomy to anatomical repair of the fascial defect, with no consensus on optimal treatment. Clinicians must remember to consider muscle hernias in their repertoire of differential diagnoses for chronic leg pain or neuropathy. A comprehensive review of muscle hernias of the leg is presented to highlight their history, occurrence, presentation, diagnosis and treatment.

Key Words: Leg; Muscle hernia; Peroneus brevis; Review uscle hernias (also known as myofascial herniations) of the Wextremities most commonly occur in the leg (between the knee and ankle). Hugo Idhe is credited with providing the original investigation and groundwork on lower extremity muscle hernias in 1929 (1). Historically, the largest contribution has been from the combined efforts of military surgeons, who observed multiple accounts of muscle hernias in actively training military recruits, and are responsible for the majority of early descriptions and reports involving this condition.

Symptomatic muscle hernias in the leg are a rare cause of chronic leg pain and neuropathy, and are not routinely encountered in surgical practice. On occasion, however, one may encounter or receive a referral for surgical management when moderate to severe symptoms persist and conservative treatment has failed. Following the early extensive documentation pioneered by military surgeons, this condition is only represented occasionally and briefly in textbooks and sporadic case reports $(2-5)$.

The present article reports case of a symptomatic muscle hernia in the leg involving the peroneus brevis (also known as fibularis brevis) causing superficial peroneal nerve (SPN) compression in an elderly male retired war veteran who was referred to our clinic for surgical management. A comprehensive literature review of muscle hernias of the leg is presented to highlight their history, occurrence, presentation, diagnosis and treatment.

\section{Les hernies musculaires de la jambe : rapport de cas et analyse bibliographique}

Les auteurs présentent le cas d'un vétéran âgé retraité ayant une hernie symptomatique du muscle court péronier responsable d'une compression du nerf péronier superficiel associée à une intervention chirurgicale précise. Les hernies symptomatiques des muscles des membres se produisent surtout dans la jambe et constituent de rares causes de douleurs chroniques de la jambe. Par le passé, les chirurgiens militaires traitants ont consigné les premiers cas de hernies de la jambe observés chez les recrues militaires actives. Une anomalie aponévrotique focale peut provoquer la herniation d'un muscle, une masse sous-cutanée palpable entraînant de la douleur et des symptômes au potentiel neuropathique associés à une atteinte nerveuse. On n'en connaît pas la véritable incidence, mais l'étiologie est classée comme secondaire à une faiblesse aponévrotique congénitale (ou constitutionnelle) ou à une anomalie aponévrotique acquise, qui découle habituellement d'un traumatisme direct ou indirect. On pense que l'occurrence la plus élevée s'observe chez les jeunes hommes physiquement actifs. L'atteinte du muscle tibial antérieur est la plus courante, mais d'autres muscles peuvent être touchés. Léchographie dynamique ou l'imagerie par résonance magnétique permet souvent de confirmer le diagnostic et d'orienter le traitement. La plupart des cas symptomatiques répondent bien à un traitement prudent, la chirurgie étant réservée aux cas réfractaires. Il existe diverses techniques chirurgicales, de la fasciotomie à la réparation anatomique de l'anomalie aponévrotique, mais aucun consensus ne se dégage quant au traitement optimal. Les cliniciens doivent se souvenir d'envisager les hernies musculaires dans le diagnostic différentiel des douleurs chroniques ou des neuropathies de la jambe. Une analyse approfondie des hernies musculaires de la jambe est présentée afin d'en faire ressortir les antécédents, l'occurrence, la présentation, le diagnostic et le traitement.

\section{CASE PRESENTATION}

A 62-year-old, retired male war veteran presented with a tender, slowly enlarging mass on his lower left lateral leg that developed over the past year. His primary complaint was numbness in the left lower lateral leg and foot, and lower lateral leg pain that increased with standing and activity. He reported no weakness. He rated his pain at eight of 10 with walking, and difficulty with ambulation, which restricted his usual recreational horseback riding, cycling, swimming and yard work. His primary care physician had attempted conservative treatment with compressive leg wraps. While the bulging visually decreased, symptoms worsened.

Pertinent medical history was significant for a history of chronic upper and lower back pain, previous cervical and lumbar surgeries, and longstanding, well-controlled sciatica. Specifically, his new symptoms were different from previous medically related symptoms experienced. No associated recent history of trauma or overly exertional activities were reported. A remote history of trauma to the affected leg occurred during a military service-related crash parachute landing. No medical treatment was rendered for this, and no associated neuromuscular deficits or sequelae were experienced. He was otherwise healthy and previously active.

Physical examination revealed a soft, mildly tender, nonreducible, $2.5 \mathrm{~cm} \times 2.0 \mathrm{~cm}$ mass on the lateral left lower extremity with decreased

\footnotetext{
${ }^{1}$ Department of General Surgery, Mayo Clinic, Rochester, Minnesota; ${ }^{2}$ Department of Plastic Surgery, Grand Rapids Medical Education Partners/

Michigan State University, Grand Rapids, Michigan; ${ }^{3}$ Division of Plastic Surgery, Portland Veteran Affairs Medical Center, Portland, Oregon, USA

Correspondence: Dr Tuan A Nguyen, Division of Plastic Surgery, Portland Veteran Affairs Medical Center, 3710 Southwest, US Veterans

Hospital Road, Portland, Oregon 97239, USA. Telephone 503-635-1955, fax 503-635-1958, e-mail tuan.nguyen6@VA.gov
} 


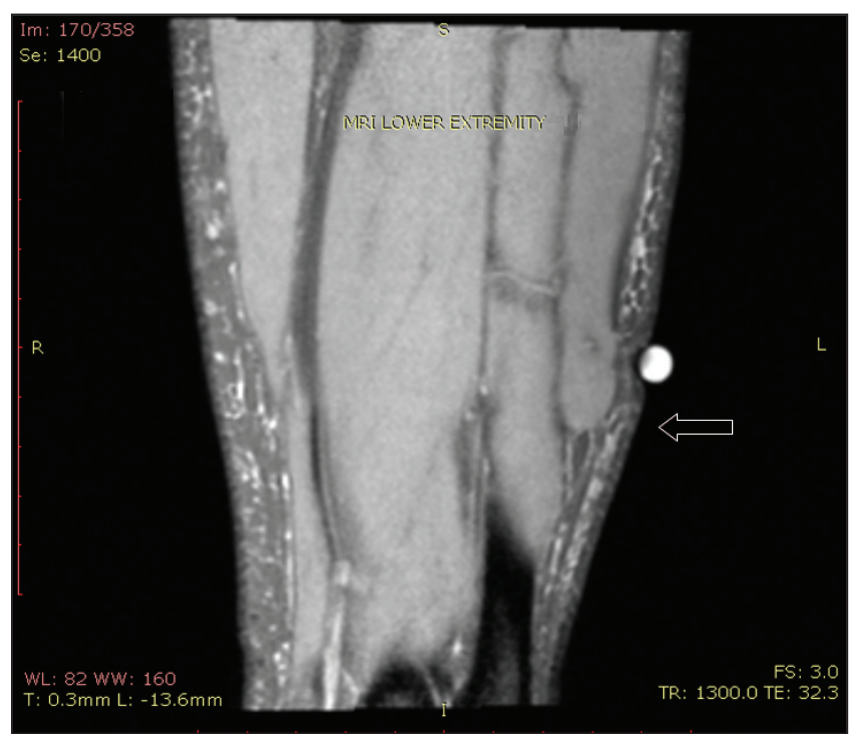

Figure 1) Magnetic resonance imaging of the left lower extremity T2 coronal plane. A skin marker had been placed directly over the peroneal musculature and demonstrated a focal contour irregularity on the anterior aspect, consistent with a fascial defect and herniation of peroneus brevis (arrow)

sensation on the left lower lateral leg, plantar aspects of the toes and dorsum of the foot. He demonstrated 5/5 motor strength, and normal patellar and achilles reflexes. The remainder of the examination was unremarkable bilaterally, with no signs of trauma or infection.

Before consultation, an equivocal ultrasonography prompted magnetic resonance imaging (MRI). MRI demonstrated focal contour irregularity anterior to peroneus brevis, and was interpreted to most likely represent a fascial defect with muscle herniation (Figure 1).

Surgical consultation was obtained secondary to persistent disabling symptoms and failure of conservative therapy. The patient consented for surgical exploration with possible fasciotomy. A longitudinal incision was made over the bulging mass. Subcutaneous tissue dissection immediately revealed underlying muscle and fascial defects. Entrapped and compressed between the proximal fascial edge and muscle, a hyperemic SPN coursed longitudinally over the muscle. Careful dissection completely released the nerve (Figures 2A and 2B). After ensuring healthy muscle appearance, a longitudinal lateral compartment-only fasciotomy was performed (Figure 2C). The wound was irrigated and hemostasis was achieved. Wound closure was performed using 3-0 synthetic polyfilament absorbable suture in buried dermal fashion, and 3-0 synthetic monofilament absorbable suture in subcuticular fashion. With no complications, the patient was discharged on the same day with instructions to maintain light activity with no strenuous activity for one month.

One month postoperatively, he reported moderate improvements in paresthesias and pain. The presence of mild left leg edema prompted the prescription of compression stockings. Four months postoperatively, he had successfully returned to his previous recreational activities. Overall, he reported significant and continual improvement, with complete resolution of paresthesias and edema. He still reported mild localized pain with physical exertion, and a small bulge remained at the hernia site. The patient was dismissed without required follow-up.

One year postoperatively, the patient reported via telephone continued resolution of paresthesias and decreased lateral leg bulging. While he continued to describe localized mild exertional pain, he expressed satisfaction with his postoperative course and results. Unfortunately, at the time of the telephone call, he was currently in the emergency room being evaluated for recent lower back and hip issues, and reported a resultant decrease in activity level.
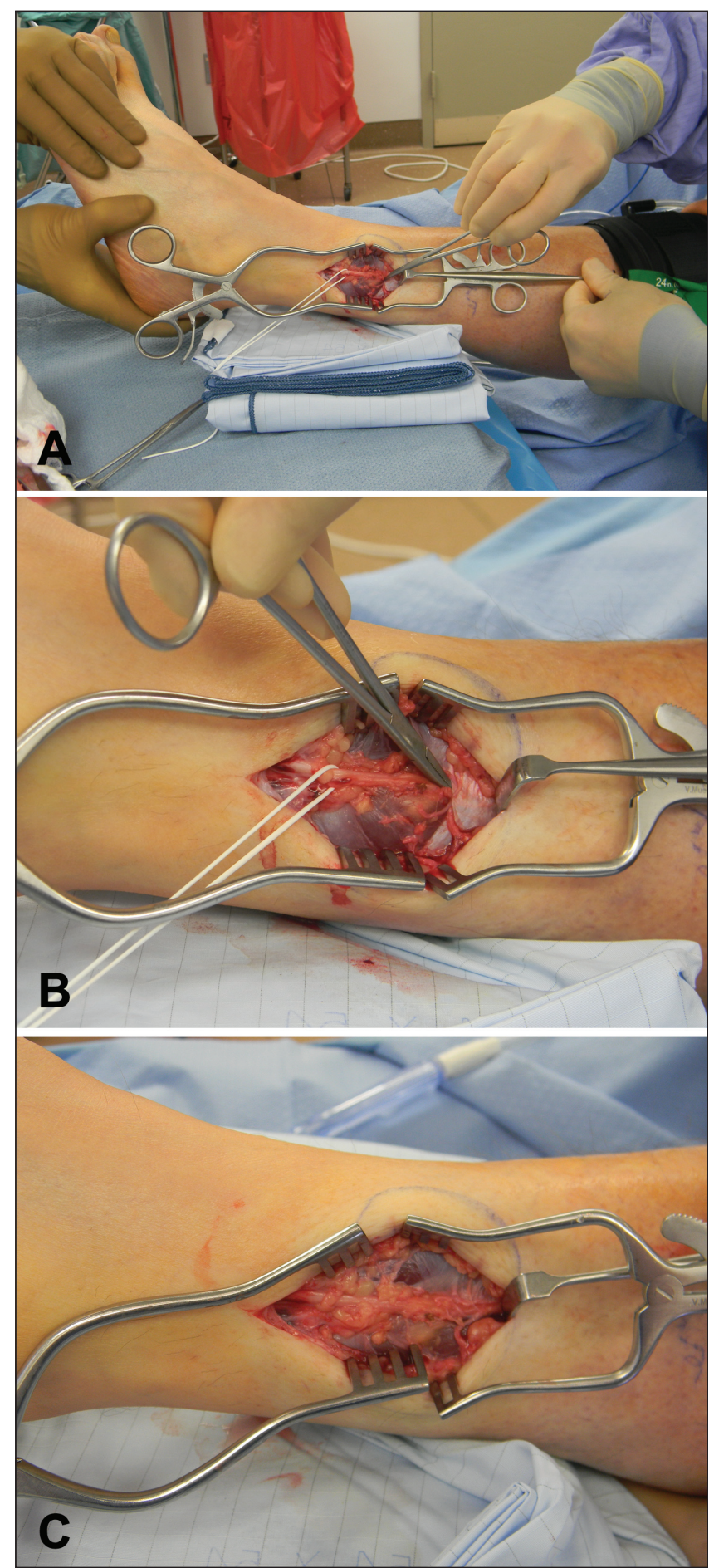

Figure 2) Intraoperative photographs. A and B Left lower extremity lateral incision with exposed peroneus brevis muscle and proximal aspect of the fascial defect (instrument). The superficial peroneal nerve has been dissected free from the proximal deep fascia and completely released (white vessel loop). C Longitudinal lateral compartment fasciotomy has been performed from the proximal and distal edges of the fascial defect using scissors, and has released the deep fascia of the left leg lateral compartment

Overall, the presented symptomatic peroneus brevis muscle hernia was successfully treated with nerve release and longitudinal lateral compartment fasciotomy. The patient's neuropathy and pain improved with satisfactory results at one year. 


\section{DISCUSSION}

The most common location of extremity (upper or lower) hernias are the legs. However, symptomatic muscle hernias of the leg are rarely encountered by the practicing surgeon and minimally represented in the literature (2-4). In 1929, Hugo Ihde, who is credited with creating the original foundation of work on this condition, reported a series of 12 patients with hernias of the leg and provided an excellent comprehensive description and critique of the history of muscle hernias leading up to his report (1). He acknowledged the earliest description by Richet in 1853 (6), and the first actual definition provided by Mourlon in 1861 as "le déplacement d'un muscle hors de son aponeurose rompue" (7). Excluding a report on leg hernias in epileptics by Fere (8), the majority of early work on leg hernias is found in French medical literature and based on military experience $(1,7,9,10)$. Much of our current knowledge is owed to the early experiences of military surgeons. In the 1940s, a surge of reports appeared in military medical journals describing lower extremity muscle hernias occurring in active military recruits $(3,4,11-16)$.

The hernia is caused by a focal fascial sheath defect. Ihde (1) classified hernias as constitutional or traumatic. While termed differently, Ihde was essentially describing the etiology of fascial defects as congenital ('constitutional') or acquired ('traumatic'). Congenital causes may be an overall general weakness in the muscular fascia (mesodermal insufficiency), or may occur at sites of perforating nerves and vessels. Acquired causes are usually secondary to trauma. Traumatic examples include penetrating trauma, closed fractures causing a fascial tear (direct trauma), or force applied to contracted muscle causing acute fascial rupture (indirect trauma) (17). Herniation is potentiated by increases in intracompartmental pressures such as muscle hypertrophy or chronic exertional compartment syndrome (CECS). For perspective, regular cardiovascular exercise and physical activity can lead to muscle hypertrophy with a $20 \%$ increase in muscle volume (18). CECS is defined as a reversible form of abnormally increased intramuscular pressure during exercise or physical exertion secondary to noncompliance of osteofascial tissues to exercise-induced increases in muscle volume (18).

The true incidence of leg hernias is not known. Interestingly, while rarely encountered, they are considered to be quite common $(12,14)$. Most are likely asymptomatic and remain undiagnosed because they are never brought to the attention of a physician (5). Leg hernias are associated with the development of exertional compartment syndromes. Of patients undergoing surgery for CECS, fascial defects have been found in $15 \%$ to $50 \%$, even with normal preoperative examinations (19-21). Athletic men, such as military soldiers, athletes, mountain climbers, skiers, and those partaking in similar occupational and sporting activities, are the demographic population believed to be at the highest risk (21).

In the leg, the tibialis anterior is the most commonly involved muscle and the most reported in literature $(1-4,12,14,15,22-42)$. The fascia of tibialis anterior is the most vulnerable to trauma because it is the weakest fascial point in the lower extremity (43). Additionally, reports have described involvement of peroneus longus $(17,44)$, peroneus brevis $(11,14,38,45)$, extensor digitorum longus $(16,46)$, gastrocnemius (38,47-51) and flexor digitorum longus (14). Bilateral (usually symmetrical) involvement $(1,3,14,26,27,29,36,52,53)$ and multiple hernias within the same muscle $(3,4,14,34,36)$ have been described in the leg. Although located in the thigh, there have also been reports of iatrogenically induced hernias involving the vastus lateralis and rectus femoris as a complication following an anterolateral thigh perforator flap $(54,55)$ and after fascia lata harvest for cruciate ligament repair (56).

Regarding the presented case report, herniation of the lateral compartment, or peroneal compartment, which includes the muscles peroneus brevis and longus, is not common. Specifically, reports of hernias involving the peroneus brevis are rare, with only four cases specifically identified in the medical literature $(11,14,38,45)$. Sherry (11) first reported a case of bilateral peroneus brevis herniation in a healthy young female with no history of trauma. In addition to nondescript mention of hernias with peroneal involvement reported by McMaster (14) and Bloem (2), only two articles describing four cases of hernias involving peroneus longus were identified $(17,44)$. Compared with other compartments, the peroneal compartment has been described as having a relative large subcutaneous surface area allowing for increased compliance, perhaps explaining the limited number of reports (57). Hernias in this location often involve the SPN and may present with additional associated sensory deficits. The etiology of the fascial defect in the lateral compartment is likely constitutional because hernias tend to be observed at the site where the SPN would normally perforate or transverse the deep fascia. Early reports noted the significance and typical presence of SPN involvement with lateral compartment muscle hernias $(11,45)$.

A muscle hernia may clinically present as a visibly palpable bulge, soft tissue mass or subcutaneous nodule. They may be solitary, bilateral or multiple. They may or not be reducible and may present with strangulated muscle (49). Patients may complain of tenderness or pain, cramping, discomfort, weakness or neuropathy. This may worsen with standing or physical activity. Tenderness may be elicited on examination and decreased sensation may occur with associated nerve involvement. If not readily apparent, herniation may be elicited with limb dependency, movements causing involved muscular contraction or certain stances. For example, pronounced herniation of the tibialis anterior may occur with resisted dorsiflexion of the foot or with the 'lunge' or 'fencing' position $(1,10)$. If palpable and easily reducible, the outlined fascial defect may be appreciated. Patients may only initially present with cosmetic concerns or concerns of a tumour (58). Dermatologists have reported the incidental discovery of asymptomatic hernias during unrelated examination $(5,22)$.

A variety of differential diagnoses for which muscular hernias have been mistaken require exclusion, including hematomas, varicosities, angiomas, arteriovenous aneurysms, epidermoid cysts, lipomas, schwannomas, tumours, ankle sprains or fractures, ruptured muscle (pseudohernia) and central neuropathy $(17,22,29,48,59)$. Although a clinical diagnosis, variable symptoms and a lengthy differential list may present a diagnostic challenge.

Evaluation with ultrasonography or MRI can be performed to confirm diagnosis, exclude pathology and guide treatment. Ultrasonography, while operator dependent, may be the best initial imaging choice secondary to relative ease and low cost $(27,28,30,46,51,60)$. Threedimensional dynamic ultrasonography with surface rendering is superior to traditional two-dimensional scans, and improves visualization of fascial planes and muscular protrusion $(30,51)$. MRI, although more expensive, is useful for confirmation or equivocal ultrasonography results $(38,42,44)$. In actuality, MRI better visualizes musculofascial demarcation, allowing quantification of fascial splitting and muscle herniation (42). MRI is superior to computed tomography because muscle and fascia have similar attenuation, which is not as easily differentiable on computed tomography (42). MRI and ultrasonography are improved with dynamic imaging techniques, which incorporate fast imaging with forced muscular movements such as dorsiflexion and plantar flexion of the ankle, and enable better visualization and pinpointing of the hernia and fascial defect $(38,51,61)$.

Most symptomatic muscle hernias are successfully treated with conservative therapy, including rest, activity restrictions and compression stockings $(17,35,40)$. Because asymptomatic hernias do not necessitate treatment, a general guideline may suggest conservative therapy only for mildly symptomatic muscle hernias. Surgical referral is warranted for patients with moderate to severe symptoms that are not amenable to a conservative therapy trial. Operative repair for cosmetic concerns has also been described and is debated $(2,11)$.

Optimal surgical treatment is controversial. A variety of surgical techniques have been described, ranging from fasciotomy to anatomical repair of the fascial defect, with no consensus. Described treatments include decompressive fasciotomy $(16,17,20,24,39,45,46,62)$, direct primary fascial repair $(1,11,15,20,26,36,39,41,47)$, tibial periosteal flap $(37,63)$, fascial patch grafting or stripping (woven strips of 
fascia) using autologous fascia lata $(1,2,4,15,31,33)$ and the use of synthetic mesh $(23,30,36,40,48,52,54)$. Partial muscle excision has been described as a solitary treatment and as an adjunct for excessive muscle volume interfering with repair $(1,14)$. Even injections of sclerosing agents (sodium morrhuate) (53), local anesthetic (triamcinolone) (50) and botulinum toxin (56) have been described.

Every operation has disadvantages and potential complications that must be weighed. Anatomical repair of the fascial defect (eg, primary repair, fascial grafting, synthetic mesh) requires close observation secondary to risks of acute or chronic compartment syndrome and hernia recurrence $(13,15,17,25,41,58)$. Fascial grafting may require additional or longer incisions, and creates new potential sites for hernia formation $(54,56)$. Synthetic mesh carries the risk of infection due to foreign body incorporation and may undesirably adhere to underlying structures.

The safest surgical option for the treatment of symptomatic muscular hernias of the leg is a longitudinal fasciotomy. This belief is the opinion of the authors and one shared by others $(16,17,39,58)$. Almost all techniques involve surgical exploration, which allows for dissection and release of the involved nerve. Fasciotomy treats the muscle hernia by enlarging the defect and eliminating risks of muscle ischemia or strangulation, which are potential causes of pain. Most importantly, it eliminates any future risks of acute or chronic compartment syndrome, which can still occur with anatomical repair of the fascia. Potential complications with fasciotomies are universal to any surgery in the lower extremity that crosses a musculofascial plane and includes exposed tendon or bone, neuromuscular damage with dysesthesias or weakness, muscle herniation and venous disease from disruption of the calf muscle pump. Incomplete pain resolution may occur with fasciotomies $(64,65)$. For the patient with high cosmetic concerns or expectations, enlarging the defect may cause more pronounced muscular bulging. Additionally, selective fasciotomy of only the involved compartment may benefit overall patient satisfaction compared with releasing multiple compartments (66). As with any surgery, the technique should be tailored to the individual and multiple viable options may exist. No absolute consensus exists regarding optimal surgical treatment.

Earlier rather than later elective surgical repair may be beneficial in patients with symptomatic muscle hernias and evidence of nerve involvement. Overstretched nerves cause severe pain, and even after the traction forces have been removed, pathological changes in the nerve may continue to progress secondary to continued inflammation

\section{REFERENCES}

1. Ihde H. On muscular hernia of the leg. Acta Chir Scand 1929;65:97-120.

2. Bloem JJ. The treatment of muscle hernias by fascial splitting. Br J Plast Surg 1976;29:291-4.

3. Kitchin ID, Richmond DA. Multiple muscle herniae. BMJ 1943;1:602-3.

4. Simon HE, Sacchet HA. Muscle hernias of the leg: Review of literature and report of twelve cases. Am J Surg 1945;67:87-97.

5. Obermayer ME, Wilson JW. Fascial hernias of the legs. JAMA 1951;145:548-9.

6. Richet. Traite d'antomie chir. 1853:124 (ref. from Choux). Quoted by Ihde.

7. Choux. De la cure radicale des hernies musculaires. Revue de Chir 1983:485.

8. Fere C. Les accidents de l'attaque 1'epilepsie liés à la contraction musculaire. Rev Chir 1900;1:50-7.

9. Hesse. Zur Frage der Radikaloperation der Hern en des Muscul tibialis anticus. (Russian orig) ref in Zentralorgan fur Chir 1921:271.

10. Pichon R. Les myocèles, en particulier les myocèles par rupture aponévrotique simples (hernias vraies des auteurs). Rev Chir 1907;36:201-29. 349-80.

11. Sherry RH. Herniation of peroneus brevis muscle: Report of a case. Bull Hosp Dis 1942;3:69-72.

12. Oldfield MC. Athletes' hernia of the tibialis anticus muscles. Br J Surg 1949;36:405-8. and vascular degeneration $(65,67)$. In their treatment of a symptomatic peroneus brevis hernia, Garfin et al (45) speculated that continued irritation of the nerve (ie, SPN) may account for failure of the fasciotomy to relieve symptoms.

While the majority of muscular hernias do not pose a therapeutic challenge, they have the potential to be lifestyle limiting and cause a significant decrease in quality of life. Unfortunately, this entity has been less well documented in the medical literature following the military surgeons who pioneered documentation of these cases in the leg. Further inquiry of the medical literature to obtain a thorough knowledge of the subject can be challenging because, in addition to the often narrow and noninclusive citing of references present in more recent literature, many articles in older military journals are often difficult to obtain secondary to lack of indexing, unavailability online and cost of retrieval. A comprehensive and extensive collection of citations has been appended to the present article to facilitate and expedite future educational review and research endeavours.

\section{CONCLUSION}

Extremity muscle hernias most commonly occur in the legs. Clinicians should include muscle hernias in the list of differential diagnoses for chronic leg pain and neuropathy. Conservative therapy is the mainstay of treatment for symptomatic hernias, although for cases refractory to conservative management and those with identified nerve involvement, surgery remains an option. A wide array of surgical treatments have been described. If surgery is warranted, a longitudinal fasciotomy is preferred by most and considered to be the safest surgical option.

AUTHOR CONTRIBUTIONS: JT Nguyen collected and analyzed the data, and wrote the final draft of the manuscript. JL Nguyen collected and analyzed the data, and reviewed the manuscript. MJ Wheatley collected the data and reviewed the manuscript. TA Nguyen designed the study, collected the data and reviewed the manuscript.

DISCLOSURES: The authors have no financial disclosures or conflicts of interest to declare.

ACKNOWLEDGEMENTS: The authors thank all library staff personnel for their contributions with article retrieval and collection.

13. Cozen LN. Herniation of muscles of lower leg. Bull US Army Med Dept 1944;77:111-2.

14. McMaster PE. Muscle hernia of the leg: A study of 21 cases and 38 hernias. U S Naval Med Bull 1943;41:404-9.

15. Schaefer WB. Nontraumatic tears of the tibial fascia. Mil Surg 1943;93:308-10.

16. Goldberg HC, Comstock GW. Herniation of muscles of the legs. War Med 1944;5:365-7.

17. Berglund HT, Stocks GW. Muscle hernia in a recreational athlete. Ortho Rev 1993;22:1246-8.

18. Schubert AG. Exertional compartment syndrome: Review of the literature and proposed rehabilitation guidelines following surgical release. Int J Sports Phys Ther 2011;6:126-41.

19. Reneman RS. The anterior and the lateral compartmental syndrome of the leg due to intensive use of muscles. Clin Orthop Relat Res 1975;113:69-80.

20. Fronek J, Mubarak SJ, Hargens AR, et al. Management of chronic exertional anterior compartment syndrome of the lower extremity. Clin Orthop Relat Res 1987;220:217-27.

21. Azar FM. Sports Medicine. In: Canale ST, Beaty JH, eds. Campbell's Operative Orthopaedics. Vol 3, 12th edn. Philadelphia: Mosby/Elsevier; 2012.

22. Alfageme F, Morales V, Garcia C, Miguelez AP, Dominguez E, Segurado A. Transfascial muscular hernia: An unusual cause for a "hide and seek" subcutaneous nodule. Dermatol Online J 2011;17:4 
23. Gilardino MS, Loftus JB, Brutus JP. Successful repair of symptomatic extremity muscle herniation with synthetic mesh. Plast Reconstr Surg 2009;123:44e-5e.

24. Dawar AK, Dawar R, Gawri K, Gupta V. Tibialis anterior muscle hernia: A rare cause of leg pain. JCR 2012;2:42-4.

25. Almdahl SM, Due J Jr, Samdal FA. Compartment syndrome with muscle necrosis following repair of hernia of tibialis anterior. Case report. Acta Chir Scand 1987;153:695.

26. Angadi DS, Rampaul RS, Akthar I, Makdhoomi K. Bilateral muscle hernias of the anterior tibial muscle. Foot Ankle Int 2007;28:520.

27. Bates DG. Dynamic ultrasound findings of bilateral anterior tibialis muscle herniation in a pediatric patient. Pediatr Radiol 2001;31:753-5.

28. Beggs I. Sonography of muscle hernias. AJR Am J Roentgenol 2003;180:395-9.

29. Ceyhan AM, Chen W, Yener M, Yildirim M, Yesildag A, Akkaya VB. Bilateral tibialis anterior muscle herniation simulating a soft tissue tumour in a young amateur football player. Australas J Dermatol 2010;51:142-4.

30. Gokhale S. Three-dimensional sonography of muscle hernias. J Ultrasound Med 2007;26:239-42.

31. Haldeman $\mathrm{KO}$, Soto-Hall R. Injuries to muscles and tendons. JAMA 1935;104:2319-24.

32. Harrington AC, Mellette JR Jr. Hernias of the anterior tibialis muscle: Case report and review of the literature. J Am Acad Dermatol 1990;22:123-4

33. Hartzell J. The use of living fascia transplant to repair a hernia of the tibialis anterior muscle. JAMA 1936;107:492-3.

34. Kim M, Hong SP, Hwang SM, Park H, Ahn SK. Tibialis anterior muscle herniation developed after trauma. Int J Dermatol 2008;47:845-7.

35. Lane JE, Woody CM, Lesher JL. Tibialis anterior muscle herniation. Dermatol Surg 2002;28:641-2.

36. Lee HS, James M. Painful bilateral herniation of the anterior tibial muscle: A case report. Foot Ankle Int 2006;27:552-5.

37. Lee JK. Anterior tibial muscle hernia treated with local periosteal rotational flap - a case report. J Korean Fract Soc 2012;25:331-4.

38. Mellado JM, Perez del Palomar L. Muscle hernias of the lower leg: MRI findings. Skeletal Radiol 1999;28:465-9.

39. Miniaci A, Rorabeck CH. Compartment syndrome as a complication of repair of a hernia of the tibialis anterior. A case report. J Bone Joint Surg 1986;68:1444-5.

40. Siliprandi L, Martini G, Chiarelli A, Mazzoleni F. Surgical repair of an anterior tibialis muscle hernia with Mersilene mesh. Plast Reconstr Surg 1993;91:154-7.

41. Wolfort GF, Mogelvang C, Filtzer HS. Anterior tibial compartment syndrome following muscle hernia repair. Arch Surg 1973;106:97-9.

42. Zeiss J, Ebraheim NA, Woldenberg LS. Magnetic resonance imaging in the diagnosis of anterior tibialis muscle herniation. Clin Orthop Relat Res 1989:249-53.

43. Verbov J. Muscle herniation of the lower legs. Br J Dermatol 1976;95:329-30.

44. Braunstein JT, Crues JV III. Magnetic resonance imaging of hereditary hernias of the peroneus longus muscle. Skelet Radiol 1995;24:601-4.

45. Garfin S, Mubarak SJ, Owen CA. Exertional anterolateralcompartment syndrome. Case report with fascial defect, muscle herniation, and superficial peroneal-nerve entrapment. J Bone Joint Surg 1977;59:404-5.

46. Henning PT, Dahm DL, Smith J. Use of postexercise ultrasonography to identify a symptomatic extensor digitorum longus muscle hernia associated with running.

PM R 2009;1:1109-11.

47. Alhadeff J, Lee CK. Gastrocnemius muscle herniation at the knee causing peroneal nerve compression resembling sciatica. Spine 1995;20:612-4.

48. Bergmann G, Ciritsis BD, Wanner GA, Simmen HP, Werner CM, Osterhoff G. Gastrocnemius muscle herniation as a rare differential diagnosis of ankle sprain: Case report and review of the literature. Patient Saf Surg 2012;6:5.

49. Conwell HE, Alldredge RH. Ruptures and tears of muscles and tendons. Am J Surg 1937;35:22-33.

50. Hong JH. Herniation of the lateral head of the gastrocnemius muscle: Is it the source of the posterolateral knee pain? Anesth Analg 2007;10:1310-1.

51. Tyson S, Subhas N. Radiologic case study. Gastrocnemius fascial defect and muscle herniation. Orthopedics 2010;33:785.

52. Marques A, Brenda E, Amarante MT. Bilateral multiple muscle hernias of the leg repaired with Marlex mesh. Br J Plast Surg 1994;47:444-6.

53. Schmier AA. Fascial hernia of both lower extremities: Injection with sodium morrhuate. JAMA 1937;109:28-9.

54. Odili J, Wilson E, Chana JS. Muscle herniation: A complication at the anterolateral thigh perforator flap donor site. J Plast Reconstr Aesth Surg 2009;62:1530-3.

55. Lipa JE, Novak CB, Binhammer PA. Patient-reported donor-site morbidity following anterolateral thigh free flaps. J Reconstr Microsurg 2005;21:365-70.

56. Burg D, Schnyder H, Buchmann R, Meyer VE. [Effective treatment of a large muscle hernia by local botulinum toxin administration] Handchir, Mikrochir, Plast Chir 1999;31:75-8.

57. Mueller M, Dunnet W. Acute on chronic peroneal compartment syndrome. Injury 2004;35:1196-9.

58. Miniaci A, Rorabeck $\mathrm{CH}$. Tibialis anterior muscle hernia: A rationale for treatment. Can J Surg 1987;30:79-80.

59. Davies JA. Peroneal compartment syndrome secondary to rupture of the peroneus longus. A case report. J Bone Joint Surg 1979;61:783-4.

60. Bianchi S, Abdelwahab IF, Mazzola CG, Ricci G, Damiani S. Sonographic examination of muscle herniation. J Ultrasound Med 1995;14:357-60.

61. Yochim SE, Jose J, Clifford PD. Muscle herniation of the extremity. Am J Orthop 2010;39:95-6.

62. Gupta RK, Singh D, Kansay R, Singh H. Cricket ball injury: A cause of symptomatic muscle hernia of the leg. Br J Sports Med 2008;42:1002-3.

63. Maric D, Madic D, Maric D, Stankovic M, Smajic M. [Anterior tibial muscle hernia - reconstruction with periosteal patch plasty]. Vojnosanit Pregl 2009;66:1015-8.

64. Golshani SD, Lee C, Sydorak R. Symptomatic forearm muscle hernia: Repair by autologous fascia lata inlay. Ann Plast Surg 1999;43:204-6.

65. Highet WB, Holmes W. Traction injuries to the lateral popliteal nerve and traction injuries to peripheral nerves after suture. Br J Surg 1943;119:212-33.

66. Packer JD, Day MS, Nguyen JT, Hobart SJ, Hannafin JA, Metzl JD. Functional outcomes and patient satisfaction after fasciotomy for chronic exertional compartment syndrome. Am J Sports Med 2013;41:430-6.

67. Nobel W. Peroneal palsy due to hematoma in the common peroneal nerve sheath after distal torsional fractures and inversion ankle sprains. J Bone Joint Surg 1966;48:1484-95. 